Check for updates

Cite this: J. Mater. Chem. A, 2019, 7, 17242

Received 26th April 2019 Accepted 4th July 2019

DOI: $10.1039 / c 9 t a 04341 a$

rsc.li/materials-a

\section{Fundamental nanoscale surface strategies for robustly controlling heterogeneous nucleation of calcium carbonate $\uparrow$}

\author{
Junjie Zhao, (D) ab Minghui Wang, (DD ${ }^{\mathrm{b}}$ Mofoluwaso S. Jebutu, ${ }^{\mathrm{b}}$ Minghui Zhu ${ }^{\mathrm{b}}$ \\ and Karen K. Gleason (D) *b
}

Tuning heterogeneous nucleation of $\mathrm{CaCO}_{3}$ could enable new biomimic structures and address inorganic fouling in desalination and petroleum industries. However, few fundamental principles exist to guide surface modification for controlling this complex nucleation process. Additionally, industrial applications often require high stability for harsh operational conditions and nanoscale thickness for low heat transfer resistance. Such robust nanoscale coating materials have not yet been reported, motivating the current study of durable ultrathin ( $\leq 100 \mathrm{~nm}$ ) organic covalent networks synthesized by initiated chemical vapor deposition (iCVD). The low surface energy of the iCVD films results in a high energy barrier for $\mathrm{CaCO}_{3}$ heterogeneous nucleation, leading to slow kinetics with extended induction periods. We also found the dominant role of electrochemical oxidation on $\mathrm{Cu}$ / $\mathrm{Ni}$ surfaces in affecting heterogeneous nucleation of $\mathrm{CaCO}_{3}$ in a hot aqueous environment. With excellent stability and passivation capability, our iCVD coatings effectively inhibit corrosion-induced heterogeneous nucleation, thus reducing the amount of $\mathrm{CaCO}_{3}$ fouling by up to 14 times at $110^{\circ} \mathrm{C}$.

Heterogeneous nucleation of $\mathrm{CaCO}_{3}$ is of fundamental importance for many industrial, geological, and biological processes. ${ }^{1-3}$ It is widely involved in the formation of biogenic minerals for exoskeletons of many marine species and avian eggshells, ${ }^{1}$ and in the development of inorganic foulants in desalination and the petroleum industry. ${ }^{4-7}$ The latter could significantly impair the heat transfer and flow rates in the equipment, and eventually affect the process efficiency and energy consumption. ${ }^{8}$ Approaches for tuning heterogeneous nucleation of $\mathrm{CaCO}_{3}$ could therefore enable the fabrication of new bio-mimic structures, and provide cost-effective, energy-

${ }^{a}$ State Key Laboratory of Chemical Engineering, College of Chemical and Biological Engineering, Zhejiang University, 38 Zheda Rd, Hangzhou, China 310027

${ }^{b}$ Department of Chemical Engineering, Massachusetts Institute of Technology, 77 Massachusetts Ave, Cambridge, MA 02139, USA. E-mail: kkg@mit.edu

$\dagger$ Electronic supplementary information (ESI) available. See DOI: 10.1039/c9ta04341a efficient solutions to inorganic fouling issues in desalination and petroleum industries.

Controlling heterogeneous nucleation of $\mathrm{CaCO}_{3}$ is a nontrivial task because of the complexity of pre-nucleation clusters/precursors and their phase transition paths to polymorphs of $\mathrm{CaCO}_{3}$ that do not follow the classical nucleation theory. ${ }^{\mathbf{1 , 9 - 1 2}}$ In addition, many factors including surface terminal groups, surface energy, roughness, and surface charge and ion interaction can affect heterogeneous nucleation of $\mathrm{CaCO}_{3}{ }^{5}$ However, it is often not possible to exclusively study one particular factor since adjustment of surface chemistry also leads to changes in other surface properties. Consequently, in spite of the previous attempts to investigate heterogeneous nucleation and growth of $\mathrm{CaCO}_{3}$ on different surfaces, ${ }^{\mathbf{1 3 - 2 1}}$ much is still unknown before a guiding principle can be developed for designing surfaces to control this dynamic process.

Surface modification for tuning heterogeneous nucleation of $\mathrm{CaCO}_{3}$ also requires robustness and thermal stability especially for applications in thermal desalination such as multistage flash (MSF) and multi-effect distillation (MED), and in oil extraction processes. In addition to withstanding wear conditions, these coatings need to be resistant to hydrolysis and erosion when exposing to seawater at temperature as high as $110{ }^{\circ} \mathrm{C},{ }^{22}$ while maintain a thickness $<1 \mu \mathrm{m}$ to reduce heat transfer resistance. ${ }^{23}$ A trade-off, however, is often present between the low film thickness desired to maintain thermal conduction and the stability of the coating layer. In most cases, film thickness was increased to achieve stability and robustness of the surface at the expense of reducing thermal conduction across the layer. ${ }^{7,24,25}$ So far, nanoscale robust coatings stable at extreme operational conditions for controlling heterogeneous nucleation of $\mathrm{CaCO}_{3}$ have not yet been reported.

Here we report a novel method to control heterogeneous nucleation of $\mathrm{CaCO}_{3}$ using nanoscale polymer coatings deposited via initiated chemical vapor deposition (iCVD). iCVD is advantageous in controlling film thickness and obtaining conformal coatings, which is crucial for applications in 
desalination and petroleum equipment. In order to avoid significant thermal insulation, the organic films applied to the metal heat exchanger surfaces must be ultrathin $(<1 \mu \mathrm{m}) \cdot{ }^{23}$ Due to the absence of surface tension, and hence dewetting effects, iCVD is ideal for forming such ultrathin pinhole-free organic films. Additionally, the metal surfaces in heat transfer equipment typically have significant roughness (on the orders of tens of $\mathrm{nm}$ or higher). To equally cover all the features in these surfaces requires a conformal coating method, such as iCVD. ${ }^{26}$

We carefully selected four iCVD polymers from over 70 candidates available for iCVD chemistry based on their surface energy, film roughness and durability. ${ }^{26}$ Polydivinylbenzene (PDVB), Poly(1,3,5-trivinyl-1,3,5-trimethylcyclotrisiloxane) $\left(\mathrm{PV}_{3} \mathrm{D}_{3}\right)$, Poly(1,3,5,7-tetra-vinyl-1,3,5,7-tetramethylcyclotetrasiloxane) $\left(\mathrm{PV}_{4} \mathrm{D}_{4}\right)$ and Poly $(1 H, 1 H, 2 H, 2 H$-perfluorodecyl acrylate) (PPFDA) were synthesized using iCVD processes similar to previous reports (experimental details shown in ESI $\dagger$ ). ${ }^{27-30}$ In a typical iCVD process, free radicals are generated from tertbutyl peroxide (TBPO) vapors flowing past an array of hot filaments. These radicals can further initiate the polymerization of the monomers adsorbed on the growth surface (Fig. 1a).

Fig. 1b shows the Fourier transform infrared (FTIR) spectra for iCVD $\mathrm{PV}_{3} \mathrm{D}_{3}, \mathrm{PV}_{4} \mathrm{D}_{4}, \mathrm{PDVB}$ and PPFDA. These spectra are consistent with prior reports, confirming the successful synthesis of the targeted polymer structures..$^{27,29-31}$ For the polymers synthesized from multi-vinyl monomers, only low absorbance was found for the $\nu(C=C)$ at $1597 \mathrm{~cm}^{-1}$ for $\mathrm{PV}_{3} \mathrm{D}_{3}$, at $1600 \mathrm{~cm}^{-1}$ for $\mathrm{PV}_{4} \mathrm{D}_{4}$, and at $1630 \mathrm{~cm}^{-1}$ for PDVB, respectively, ${ }^{27,29,31}$ indicating negligible pendant vinyl groups in these polymers after iCVD. For iCVD PPFDA, complete loss of the

(a)

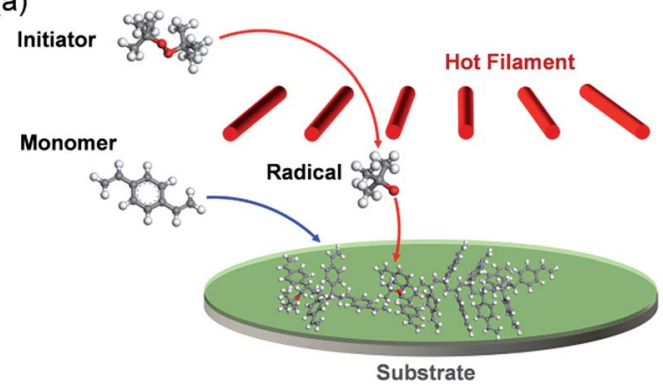

(b)

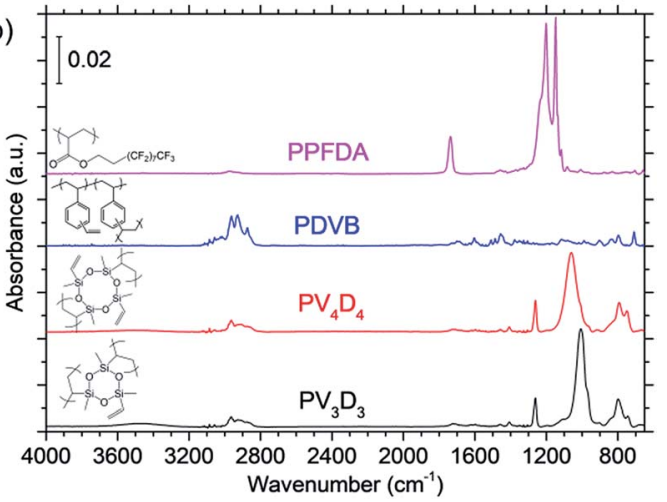

Fig. 1 (a) Schematic illustration for initiated chemical vapor deposition (iCVD). (b) FTIR spectra for iCVD $\mathrm{PV}_{3} \mathrm{D}_{3}, \mathrm{PV}_{4} \mathrm{D}_{4}, \mathrm{PDVB}$ and PPFDA.
$\nu(\mathrm{C}=\mathrm{C})$ at $1639 \mathrm{~cm}^{-1}$ in the monomer was achieved after polymerization, ${ }^{32}$ revealing full conversion of the double bonds.

We deposited these iCVD polymer films on $\mathrm{Cu} / \mathrm{Ni}$ alloy foils that have similar composition with the tube materials used in the heat exchangers in MSF plants. ${ }^{33}$ Film thickness was controlled at ca. $100 \mathrm{~nm}$ based on in situ interferometry during the iCVD processes. This thickness was chosen because it ensured the formation of continuous, pinhole-free films for good passivation while maintaining small heat transfer resistance on the $\mathrm{Cu} / \mathrm{Ni}$ surface.$^{23}$ Grazing incidence X-ray diffraction (GIXRD) for the iCVD-coated $\mathrm{Cu} / \mathrm{Ni}$ foils is shown in Fig. S1. $\dagger$ The diffraction peaks shown at low $2 \theta$ angles for PPFDA represent the lamellar structure of this polymer, ${ }^{34}$ while the other iCVD polymer films are amorphous. Atomic force microscopy (AFM) reveals that pristine $\mathrm{Cu} / \mathrm{Ni}$ alloy foil has aligned surface features with a roughness of $37.8 \pm 11.0 \mathrm{~nm}$ (Fig. S2†). The intrinsic roughness of the iCVD polymer films measured on $\mathrm{Si}$ substrates is generally less than $0.5 \mathrm{~nm}$, except for iCVD PPFDA $(15.8 \pm 1.5 \mathrm{~nm})$ due to its crystalline structure (Fig. S3†). The roughness of iCVD coated $\mathrm{Cu} / \mathrm{Ni}$ foils is quite similar to the uncoated substrate (Table S1 $\dagger$ ), confirming the combination of the conformal coverage and the low intrinsic roughness of the iCVD surface modification layer.

The surface energy of the iCVD polymers was determined using contact angle measurements with multiple liquids with known surface tension, and compared with common commercial polymers $^{35,36}$ (Fig. S4 $\dagger$ ). Polytetrafluoroethylene (PTFE) and polydimethylsiloxane (PDMS) represent the lower bound of surface energy ( $c a .20 \mathrm{mN} \mathrm{m}^{-1}$ ) among common polymer materials. The surface energy of our cyclosiloxane-based iCVD $\mathrm{PV}_{3} \mathrm{D}_{3}\left(21.89 \pm 2.91 \mathrm{mN} \mathrm{m}^{-1}\right)$ and $\mathrm{PV}_{4} \mathrm{D}_{4}\left(19.96 \pm 2.82 \mathrm{mN} \mathrm{m}^{-1}\right)$ is quite comparable with that of PTFE and PDMS, while the surface energy of iCVD PPFDA $\left(9.36 \pm 1.32 \mathrm{mN} \mathrm{m}^{-1}\right)$ was found at least 50\% smaller than PTFE and PDMS.

We investigated the adhesion between $\mathrm{CaCO}_{3}$ and the iCVD polymer films using molecular force probe (MFP). iCVD-coated MFP cantilevers were employed to probe the surface of a $\mathrm{CaCO}_{3}$ single crystal (dimension: $10 \mathrm{~mm} \times 10 \mathrm{~mm} \times 0.5 \mathrm{~mm}$ ) in an aqueous solution of saturated $\mathrm{CaCO}_{3}$ (Fig. 2a). Force response was recorded when the MFP probe was approaching and retracting from the $\mathrm{CaCO}_{3}$ surface. Work of adhesion ( $\left.W_{\mathrm{ad}}\right)$ was calculated from the measured adhesion forces using JohnsonKendall-Roberts (JKR) model (details shown in the ESI $\dagger$ ). ${ }^{37}$ As shown in Fig. 2b, iCVD PPFDA exhibits ultra-low $W_{\text {ad }}(5.14 \pm$ $1.54 \mathrm{mN} \mathrm{m}^{-1}$ ), indicating a non-sticking surface for $\mathrm{CaCO}_{3}$. This surface property is highly desired for desalination and petroleum equipment, as it could prevent the $\mathrm{CaCO}_{3}$ precipitated in solution from adhering to the substrate surface. Compared with untreated $\mathrm{Cu}, \mathrm{SiO}_{2}$ coated $\mathrm{Cu}$, and $\mathrm{Cu}$ coupled with triethoxyvinylsilane, ${ }^{38}$ the $W_{\text {ad }}$ between $\mathrm{CaCO}_{3}$ and all the four iCVD polymers are significantly smaller (Table $\mathrm{S} 2 \dagger$ ). The $W_{\text {ad }}$ for $\mathrm{CaCO}_{3}$ on iCVD PPFDA, $\mathrm{PV}_{4} \mathrm{D}_{4}$ and $\mathrm{PV}_{3} \mathrm{D}_{3}$ increases consistently with the surface energy of the corresponding polymer. Although iCVD PDVB exhibits higher surface energy than iCVD $\mathrm{PV}_{3} \mathrm{D}_{3}$, the $W_{\text {ad }}$ for $\mathrm{CaCO}_{3}$ on iCVD PDVB was found lower than that on iCVD $\mathrm{PV}_{3} \mathrm{D}_{3}$. This is possibly because the surface polarity of iCVD PDVB is significantly lower than $\mathrm{PV}_{3} \mathrm{D}_{3}$ (Table $\mathrm{S} 3 \dagger$ ). Polar 


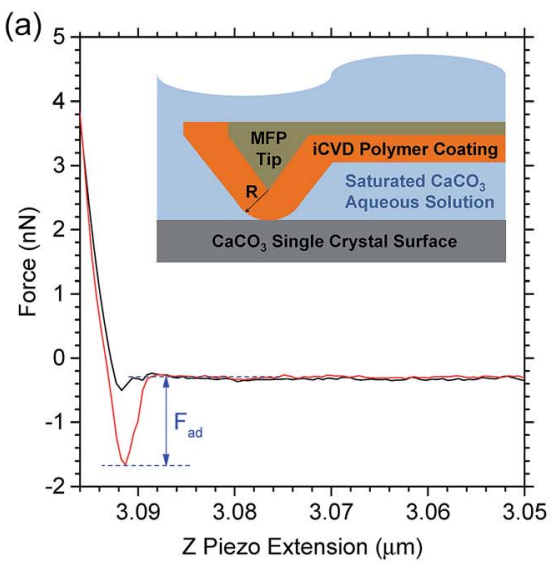

(d)

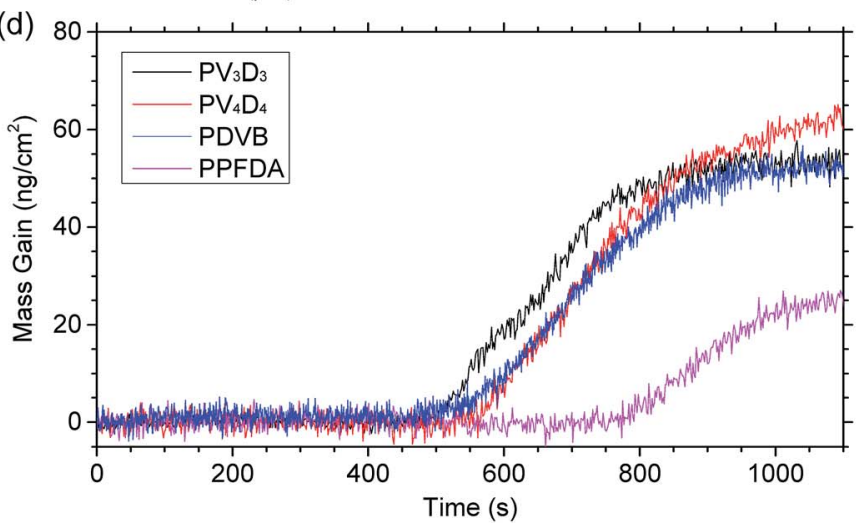

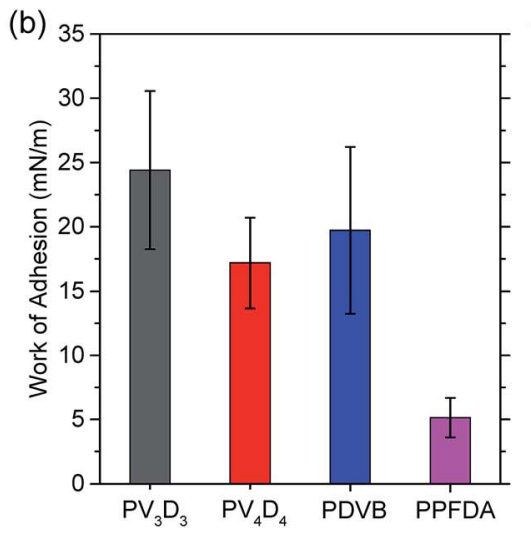

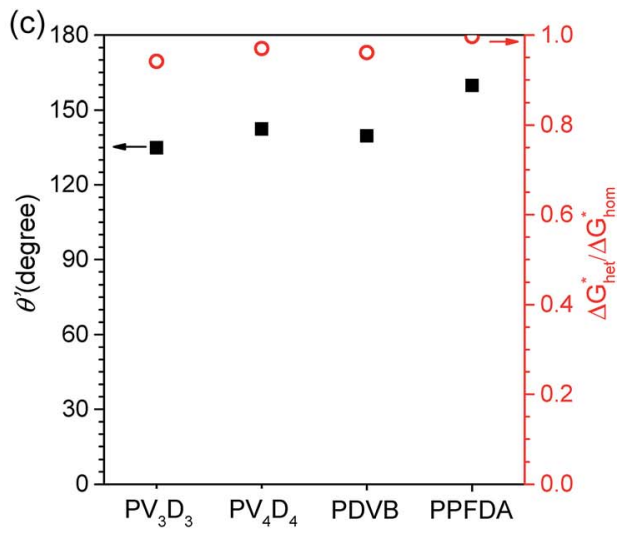

(e)

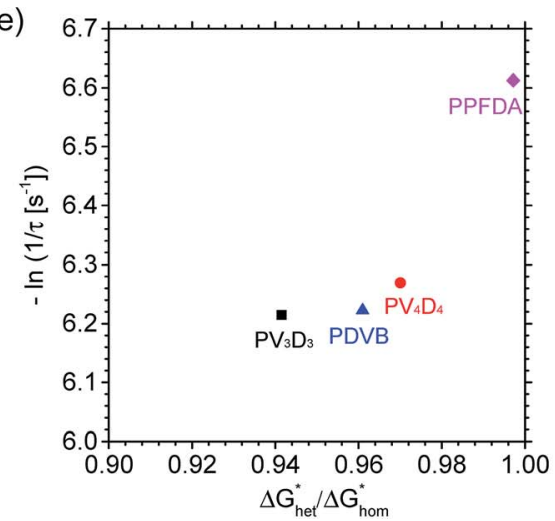

Fig. 2 (a) Force response in a typical molecular force probe (MFP) measurement. Inset is a schematic for the adhesion measurement using MFP in aqueous environment. (b) Work of adhesion for $\mathrm{CaCO}_{3}$ on iCVD polymers calculated from adhesion forces using Johnson-Kendall-Roberts (JKR) model. (c) Contact angles of $\mathrm{CaCO}_{3}$ on iCVD polymers calculated from Young-Dupré equation (black squares) and the energy barrier ratio of heterogeneous nucleation to homogeneous nucleation based on classical nucleation theory (red circles). (d) Mass change on QCM crystals during the nucleation and growth of $\mathrm{CaCO}_{3}$ in a flow cell. (e) Correlation between the induction period $\tau$ and the nucleation energy barrier ratio.

interactions originate from the surface charge of $\mathrm{CaCO}_{3}$ (ref. 39) and the induced orientation of molecular dipoles in polymers. ${ }^{40}$ Large opposite polarity leads to strong adhesion, resulting in high work of adhesion. ${ }^{41}$

With the analyzed $W_{\text {ad }}$ and the reported interfacial energy between water and $\mathrm{CaCO}_{3}\left(\gamma_{\mathrm{LS}}=83 \mathrm{mN} \mathrm{m}{ }^{-1}\right),{ }^{42}$ we estimated the contact angle $\left(\theta^{\prime}\right)$ of $\mathrm{CaCO}_{3}$ on the iCVD polymers using Young-Dupré equation (Fig. 2c).

$$
W_{\text {ad }}=\gamma_{\mathrm{LS}}\left(1+\cos \theta^{\prime}\right)
$$

We found the $\theta^{\prime}$ is higher than $130^{\circ}$ for all the four iCVD polymers (Fig. 2c), indicating that these iCVD surfaces are not favored for $\mathrm{CaCO}_{3}$. Assuming that the heterogeneous nucleation of $\mathrm{CaCO}_{3}$ follows the classical nucleation theory, we further estimated the energy barrier as a ratio of the change of free energy during $\mathrm{CaCO}_{3}$ heterogeneous nucleation to that during $\mathrm{CaCO}_{3}$ homogeneous nucleation $\left(\Delta G_{\mathrm{Het}}^{*} / \Delta G_{\mathrm{Hom}}^{*}\right)$. Here we use a simplified model with a spherical nuclei cap formed on a flat mold (Scheme S1 $\dagger$ ) to describe heterogeneous nucleation of $\mathrm{CaCO}_{3}$ on iCVD polymer surfaces. The energy barrier for heterogeneous nucleation $\left(\Delta G_{\text {Het }}^{*}\right)$ is given by

$$
\Delta G_{\mathrm{Het}}^{*}=\Delta G_{\mathrm{Hom}}^{*} \times g(m)
$$

where $\Delta G_{\mathrm{Hom}}^{*}$ is the energy barrier for homogenous nucleation, the geometric factor $g(m)$ is defined as a function of the contact angle $\left(m=\cos \theta^{\prime}\right)$

$$
g(m)=\frac{1}{4}(1-m)^{2}(2+m)
$$

As shown in Fig. 2 c, $\Delta G_{\text {Het }}^{*} / \Delta G_{\text {Hom }}^{*}$ is over $90 \%$ for all the tested iCVD surfaces, indicating that these iCVD polymer coatings could effectively inhibit heterogeneous nucleation of $\mathrm{CaCO}_{3}$.

Fig. $2 \mathrm{~d}$ shows the mass gain measured via quartz crystal microbalance (QCM) during the nucleation and growth of $\mathrm{CaCO}_{3}$ in a flow cell. A delay of nucleation was observed for all the four iCVD-coated QCM surfaces. iCVD PPFDA exhibits the longest induction period among the iCVD polymers, consistent with the highest nucleation energy found from adhesion analysis. Since induction time $(\tau)$ is inversely proportional to nucleation rate, ${ }^{43}$ we found that the nucleation rate of $\mathrm{CaCO}_{3}$ decreases with the increase of $\mathrm{CaCO}_{3}$ contact angle on the iCVD polymers. $\tau$ can also be directly correlated with $\Delta G_{\mathrm{Het}}^{*} / \Delta G_{\mathrm{Hom}}^{*}$ through eqn (4) (derivation shown in ESI†) 


$$
-\ln \frac{1}{\tau}=\varphi \frac{\Delta G_{\mathrm{Het}}^{*}}{\Delta G_{\mathrm{Hom}}^{*}}-\ln A^{\prime}
$$

where $A^{\prime}$ is a modified kinetic parameter, $\varphi$ is the ratio of $\Delta G_{\mathrm{Hom}}^{*}$ to the product of Boltzmann constant and temperature $\left(k_{\mathrm{B}} T\right)$. Both $A^{\prime}$ and $\varphi$ are constant for $\mathrm{CaCO}_{3}$ nucleation at given temperature. As shown in Fig. 2e, $-\ln (1 / \tau)$ increases with $\Delta G_{\mathrm{Het}}^{*} / \Delta G_{\mathrm{Hom}}^{*}$, confirming that the nanoscale surface modification using iCVD enables the control of $\mathrm{CaCO}_{3}$ nucleation kinetics.

In order to demonstrate the potential of the nanoscale iCVD coatings for controlling $\mathrm{CaCO}_{3}$ nucleation in thermal desalination, we further evaluated these iCVD polymer films in conditions similar to MSF processes. Uncoated and iCVD coated $\mathrm{Cu} / \mathrm{Ni}$ foils were immersed in a mixed aqueous solution of $10 \mathrm{mmol} \mathrm{L}^{-1} \mathrm{CaCl}_{2}$ and $2 \mathrm{mmol} \mathrm{L}^{-1} \mathrm{NaHCO}_{3}$, which mimics the concentration of $\mathrm{Ca}^{2+}$ and $\mathrm{HCO}_{3}{ }^{-}$typically found in sea water. The pressure of the distillation apparatus was tuned to obtain different boiling points of the synthetic seawater $\left(50-110{ }^{\circ} \mathrm{C}\right)$, similar to the typical conditions in the external brine heaters and the heat exchangers in an MSF plant. ${ }^{5}$

Fig. 3a-j compare the surface of the $\mathrm{Cu} / \mathrm{Ni}$ foils after the $\mathrm{CaCO}_{3}$ fouling test at $110{ }^{\circ} \mathrm{C}$. Scanning electron microscopy (SEM) and energy dispersive X-ray (EDX) mapping show large amount of $\mathrm{CaCO}_{3}$ particles with different morphology on the uncoated $\mathrm{Cu} / \mathrm{Ni}$ (Fig. 3a). The small particles (average size $=544$ $\pm 170 \mathrm{~nm}$ ) formed densely on the substrate surface (Fig. S5 $\dagger$ ) were found to be the main corrosion product of $\mathrm{Cu}_{2} \mathrm{O}$ via GIXRD
(Fig. 31). The $\mathrm{CaCO}_{3}$ crystals observed on top of the corrosion products were identified as aragonite and calcite. This is consistent with previous reports of inorganic foulant layers on top of corrosion products in $\mathrm{MSF},{ }^{33,44}$ and suggests that the corrosion products act as nucleation sites for $\mathrm{CaCO}_{3}$. The amounts of the $\mathrm{CaCO}_{3}$ were further quantitatively analyzed by digesting the foulant in dilute nitric acid and using inductivelycoupled plasma optical emission spectroscopy (ICP-OES). Fig. 3k shows that the Ca surface density on uncoated $\mathrm{Cu} / \mathrm{Ni}$ is $2.38 \pm$ $0.34 \mu \mathrm{g} \mathrm{cm}^{-2}, 6.84 \pm 0.72 \mu \mathrm{g} \mathrm{cm}^{-2}$ and $28.3 \pm 1.4 \mu \mathrm{g} \mathrm{cm}^{-2}$ after $\mathrm{CaCO}_{3}$ fouling tests at $50{ }^{\circ} \mathrm{C}, 75{ }^{\circ} \mathrm{C}$ and $110{ }^{\circ} \mathrm{C}$, respectively.

In contrast to uncoated $\mathrm{Cu} / \mathrm{Ni}, \mathrm{Cu} / \mathrm{Ni}$ coated with iCVD $\mathrm{PV}_{3} \mathrm{D}_{3}, \mathrm{PV}_{4} \mathrm{D}_{4}$ and PDVB show significantly reduced amounts of $\mathrm{CaCO}_{3}$ crystals after the fouling test at $110{ }^{\circ} \mathrm{C}$ (Fig. $3 \mathrm{~b}-\mathrm{d}$ and $\mathrm{g}-$ i). ICP-OES results reveal that $\mathrm{iCVD}^{\mathrm{PV}} \mathrm{V}_{3} \mathrm{D}_{3}$ coated $\mathrm{Cu} / \mathrm{Ni}$ enables almost 14 times lower $\mathrm{CaCO}_{3}$ fouling than uncoated $\mathrm{Cu} / \mathrm{Ni}$ at $110{ }^{\circ} \mathrm{C}$. For the $\mathrm{CaCO}_{3}$ fouling test at $75{ }^{\circ} \mathrm{C}$, the $\mathrm{Ca}$ surface density on $\mathrm{Cu} / \mathrm{Ni}$ decreases by over 8 times with the protection of iCVD $\mathrm{PV}_{3} \mathrm{D}_{3}$ coatings. This significant reduction of $\mathrm{CaCO}_{3}$ formation in the temperature range for the brine heaters and the first few MSF stages where scaling is most likely to happen suggests that longer operational periods with fewer shutdowns for maintenance could be achieved for future MSF plants. For the $\mathrm{CaCO}_{3}$ fouling test at $50{ }^{\circ} \mathrm{C}$, the $\mathrm{Ca}$ surface density is all below $0.8 \mu \mathrm{g} \mathrm{cm}{ }^{-2}$ for $\mathrm{Cu} / \mathrm{Ni}$ coated with iCVD $\mathrm{PV}_{3} \mathrm{D}_{3}, \mathrm{PV}_{4} \mathrm{D}_{4}$ and $\mathrm{PDVB}$, at least 3 times lower than uncoated $\mathrm{Cu} / \mathrm{Ni}$ surfaces. These results confirm that our iCVD polymer coatings could be
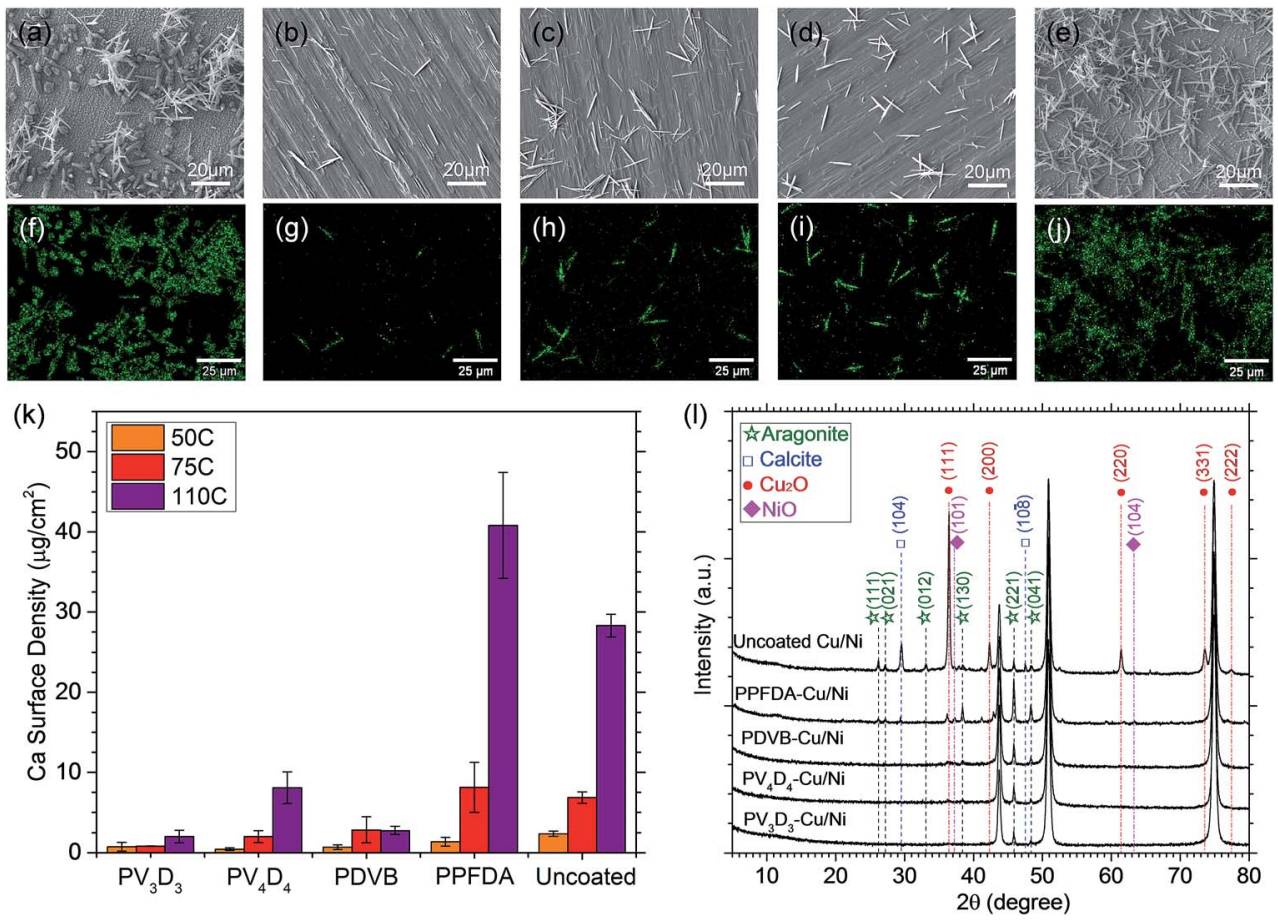

Fig. 3 (a-e) Scanning electron microscopy (SEM) images for (a) uncoated Cu/Ni and (b-e) iCVD coated Cu/Ni foil surfaces ((b) PV $3 \mathrm{D}_{3}$, (c) PV $4 \mathrm{D}_{4}$, (d) PDVB and (e) PPFDA) after $\mathrm{CaCO}_{3}$ scaling tests at $110^{\circ} \mathrm{C}$. ( $\left.f-j\right)$ Energy dispersive $\mathrm{X}$-ray (EDX) mapping images for (f) uncoated $\mathrm{Cu} / \mathrm{Ni}$ and ( $\mathrm{g}-\mathrm{j}$ ) iCVD coated $\mathrm{Cu} / \mathrm{Ni}$ foil surfaces ((g) $\mathrm{PV}_{3} \mathrm{D}_{3}$, (h) $\mathrm{PV}_{4} \mathrm{D}_{4}$, (i) PDVB and (j) PPFDA) after $\mathrm{CaCO}_{3}$ scaling tests at $110^{\circ} \mathrm{C}$. (k) Ca surface density on uncoated and iCVD coated $\mathrm{Cu} / \mathrm{Ni}$ foils after $\mathrm{CaCO}_{3}$ scaling tests in different conditions analogous to MSF. (l) GIXRD patterns for uncoated and iCVD coated $\mathrm{Cu} / \mathrm{Ni}$ foils after $\mathrm{CaCO}_{3}$ scaling tests at $110^{\circ} \mathrm{C}$. 
applied to inhibit $\mathrm{CaCO}_{3}$ fouling in MSF plants for the entire operational temperature range.

Compared with uncoated $\mathrm{Cu} / \mathrm{Ni}$ surface where both calcite and aragonite were observed, aragonite appears to be the dominant phase on iCVD coated $\mathrm{Cu} / \mathrm{Ni}$. This can be explained by the known phase transition from aragonite to calcite in hot aqueous fluid, ${ }^{45}$ as calcite is more thermodynamically stable than aragonite. ${ }^{1}$ The calcite observed on uncoated $\mathrm{Cu} / \mathrm{Ni}$ was possibly converted from the aragonite, while significant nucleation delay on iCVD coated $\mathrm{Cu} / \mathrm{Ni}$ resulted in aragonite as the dominant phase.

We noticed that iCVD PPFDA coated $\mathrm{Cu} / \mathrm{Ni}$ shows promoted heterogeneous nucleation of $\mathrm{CaCO}_{3}$ for the fouling tests at $75^{\circ} \mathrm{C}$ and $110{ }^{\circ} \mathrm{C}$ compared with uncoated $\mathrm{Cu} / \mathrm{Ni}$. This is because this acrylate polymer is prone to hydrolysis in hot aqueous environment. Optical microscopy reveals the erosion of iCVD PPFDA films during the exposure to boiling water. Consequently, the loss of passivation leads to the corrosion of $\mathrm{Cu} / \mathrm{Ni}$, as confirmed by GIXRD (Fig. 31). The degraded polymer chains in the vicinity of the surface and the corrosion products of $\mathrm{Cu} / \mathrm{Ni}$ are likely to promote the heterogeneous nucleation of $\mathrm{CaCO}_{3}$. In contrary, no corrosion products were found on $\mathrm{Cu} / \mathrm{Ni}$ coated with iCVD $\mathrm{PV}_{3} \mathrm{D}_{3}, \mathrm{PV}_{4} \mathrm{D}_{4}$ and $\mathrm{PDVB}$, indicating that these cross-linked iCVD polymer films have excellent stability and allow good passivation for $\mathrm{Cu} / \mathrm{Ni}$.

In order to better understand the role of surface corrosion in promoting the heterogeneous nucleation of $\mathrm{CaCO}_{3}$, We applied electrochemical methods to investigate the corrosion rates for uncoated and $\mathrm{iCVD}$ coated $\mathrm{Cu} / \mathrm{Ni}$ foils (film thickness $=c a .100$ $\mathrm{nm}$ ) before and after exposure to boiling water at $100^{\circ} \mathrm{C}$ for $2 \mathrm{~h}$.
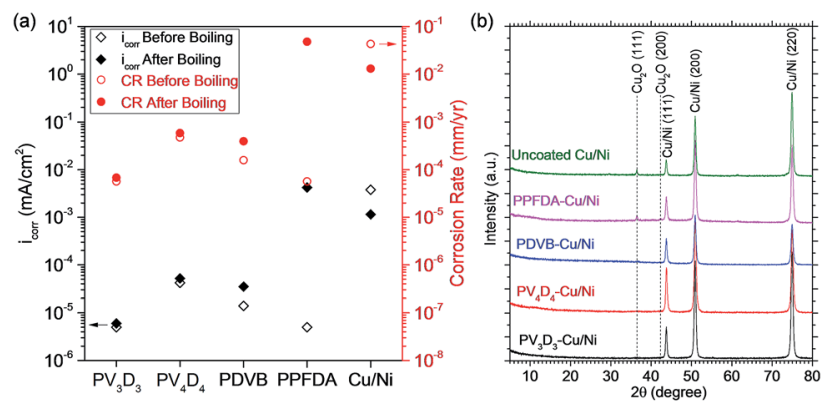

(c)

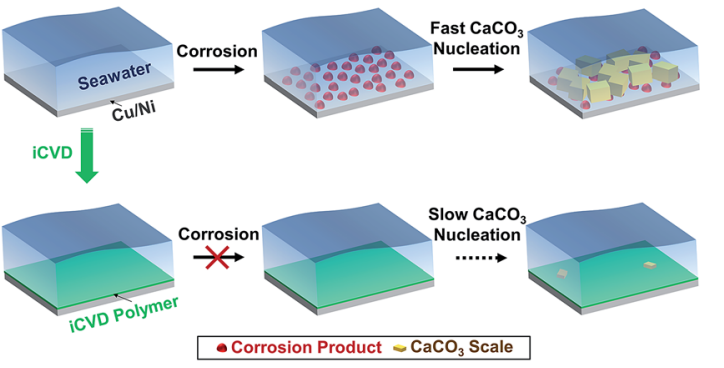

Fig. 4 (a) Corrosion current density and corrosion rates for uncoated and iCVD coated Cu/Ni foils before and after exposure to boiling water for 2 h. (b) GIXRD for uncoated and iCVD coated Cu/Ni foils after exposure to boiling water for 2 h. (c) Schematic illustration for corrosion-induced heterogeneous nucleation of $\mathrm{CaCO}_{3}$ on $\mathrm{Cu} / \mathrm{Ni}$ surface and iCVD polymer coatings for passivation and nucleation control.
Fig. 4a shows the corrosion current density $\left(i_{\text {corr }}\right)$ extracted from linear sweep voltammetry (LSV) via Tafel analysis and the corresponding corrosion rates. Compared with uncoated $\mathrm{Cu} / \mathrm{Ni}$, the $i_{\text {corr }}$ of iCVD-coated $\mathrm{Cu} / \mathrm{Ni}$ foils prior to the exposure to boiling water is 2-3 orders of magnitude smaller. Notably, asdeposited iCVD PPFDA shows extremely low $i_{\text {corr }}\left(5.0 \times 10^{-6}\right.$ $\mathrm{mA} \mathrm{cm}{ }^{-2}$ ). This excellent passivation performance prior to the exposure to hot aqueous environment also explains the abovementioned slow nucleation kinetics of $\mathrm{CaCO}_{3}$ on iCVD PPFDA at room temperature. After exposure to boiling water for $2 \mathrm{~h}$, however, the $i_{\text {corr }}$ for iCVD PPFDA increases dramatically from $5.0 \times 10^{-6} \mathrm{~mA} \mathrm{~cm}^{-2}$ to $4.2 \times 10^{-3} \mathrm{~mA} \mathrm{~cm}^{-2}$. GIXRD also shows $\mathrm{Cu}_{2} \mathrm{O}$ corrosion product on PPFDA coated $\mathrm{Cu} / \mathrm{Ni}$ (Fig. $4 \mathrm{~b}$ ). These results again confirm the loss of passivation for $\mathrm{Cu} / \mathrm{Ni}$ due to the erosion of iCVD PPFDA.

In addition, we found that the trend of $\mathrm{CaCO}_{3}$ nucleation and growth on iCVD-coated $\mathrm{Cu} / \mathrm{Ni}$ surfaces at $110{ }^{\circ} \mathrm{C}$ agrees well with the corresponding corrosion rate measured after exposure to boiling water. iCVD $\mathrm{PV}_{3} \mathrm{D}_{3}$ coated $\mathrm{Cu} / \mathrm{Ni}$ exhibits the lowest corrosion rate $\left(6.8 \times 10^{-5} \mathrm{~mm}\right.$ per year) among the four iCVD coatings, which is 191 times slower than uncoated $\mathrm{Cu} / \mathrm{Ni}$. The ultra-low corrosion rate explains the lowest amount of $\mathrm{CaCO}_{3}$ formed on $\mathrm{iCVD} \mathrm{PV}_{3} \mathrm{D}_{3}$ coated $\mathrm{Cu} / \mathrm{Ni}$ at $110{ }^{\circ} \mathrm{C}$, although the nucleation energy barrier and the induction time at room temperature for iCVD $\mathrm{PV}_{3} \mathrm{D}_{3}$ were found lower than other iCVD polymers. These results clearly indicate the dominant role of surface electrochemical oxidation of $\mathrm{Cu} / \mathrm{Ni}$ in the heterogeneous nucleation of $\mathrm{CaCO}_{3}$. The mechanism is proposed in Fig. 4c for the corrosion-induced heterogeneous nucleation of $\mathrm{CaCO}_{3}$ on $\mathrm{Cu} / \mathrm{Ni}$ in hot aqueous conditions and the inhibition strategy using nanoscale iCVD coatings.

Finally, we evaluated the robustness of our iCVD anti-scaling coatings in high-temperature fouling tests for extended hours. After exposure to the synthetic seawater at $110{ }^{\circ} \mathrm{C}$ for $72 \mathrm{~h}$, severe corrosion was found on uncoated $\mathrm{Cu} / \mathrm{Ni}$ foils (Fig. S7b $\dagger$ ). Consequently, the Ca surface density on uncoated $\mathrm{Cu} / \mathrm{Ni}$ is as high as $39.6 \mu \mathrm{g} \mathrm{cm}{ }^{-2}$, indicating large amount of $\mathrm{CaCO}_{3}$ foulant (Fig. S7a $\dagger$ ). In contrast, the Ca surface density is generally less than $10 \mu \mathrm{g} \mathrm{cm}{ }^{-2}$ for $\mathrm{Cu} / \mathrm{Ni}$ coated with iCVD $\mathrm{PV}_{3} \mathrm{D}_{3}, \mathrm{PV}_{4} \mathrm{D}_{4}$ and PDVB. Especially, the suppression of $\mathrm{CaCO}_{3}$ fouling is maintained over 10 times under the protection with iCVD $\mathrm{PV}_{3} \mathrm{D}_{3}$, demonstrating the excellent stability of nanoscale iCVD coatings for longterm control of $\mathrm{CaCO}_{3}$ nucleation in thermal desalination.

\section{Conclusions}

In summary, we have developed a series of robust nanoscale iCVD polymer coatings for controlling heterogeneous nucleation of $\mathrm{CaCO}_{3}$ in various conditions. Polymer coating materials with low surface energy and polarity were found with low adhesion to $\mathrm{CaCO}_{3}$ and high nucleation barrier for heterogeneous nucleation of $\mathrm{CaCO}_{3}$. In addition, for practical conditions in thermal desalination, the chemical stability and the surface passivation ability to inhibit surface corrosion are also important factors for designing anti-fouling coatings to control $\mathrm{CaCO}_{3}$ surface nucleation. Crosslinked covalent organic networks like iCVD $\mathrm{PV}_{3} \mathrm{D}_{3}$ have been synthesized as robust nanoscale coatings 
that exhibit both ultra-low corrosion rate of $\mathrm{Cu} / \mathrm{Ni}$ and excellent performance for controlling $\mathrm{CaCO}_{3}$ nucleation in hot aqueous environment. The iCVD surface modification reported here represents a promising strategy to control $\mathrm{CaCO}_{3}$ fouling in thermal desalination and petroleum industry.

\section{Conflicts of interest}

There are no conflicts to declare.

\section{Acknowledgements}

The authors thank Kuwait Foundation for the Advancement of Sciences (KFAS) (P31475EC01) for funding support through the Kuwait-MIT Center for Natural Resources and the Environment at MIT. JZ acknowledges the startup funding from Zhejiang University and the funding supported by State Key Laboratory of Chemical Engineering.

\section{References}

1 L. B. Gower, Chem. Rev., 2008, 108, 4551.

2 N. A. J. M. Sommerdijk and G. de With, Chem. Rev., 2008, 108, 4499.

3 A. V. Radha and A. Navrotsky, Rev. Mineral. Geochem., 2013, 77, 73.

4 D. M. Warsinger, J. Swaminathan, E. Guillen-Burrieza, H. A. Arafat and J. H. Lienhard V, Desalination, 2015, 356, 294.

5 J. Zhao, M. Wang, H. M. S. Lababidi, H. Al-Adwani and K. K. Gleason, Desalination, 2018, 442, 75.

6 J. Li, M. Tang, Z. Ye, L. Chen and Y. Zhou, J. Dispersion Sci. Technol., 2017, 38, 661.

7 M. M. Vazirian, T. V. J. Charpentier, M. de Oliveira Penna and A. Neville, J. Pet. Sci. Eng., 2016, 137, 22.

8 F. Rahman and Z. Amjad, in Sci. Technol. Ind. Water Treat., CRC Press, 2010, pp. 271-396.

9 D. Gebauer, A. Völkel and H. Cölfen, Science, 2008, 322, 1819.

10 D. Gebauer, P. N. Gunawidjaja, J. Y. P. Ko, Z. Bacsik, B. Aziz, L. Liu, Y. Hu, L. Bergström, C.-W. Tai, T.-K. Sham, M. Edén and N. Hedin, Angew. Chem., Int. Ed., 2010, 49, 8889.

11 M. H. Nielsen, S. Aloni and J. J. D. Yoreo, Science, 2014, 345, 1158.

12 R. Jens, K. Matthias and N. Luc, Angew. Chem., Int. Ed., 2014, 53, 12380.

13 D. M. Duffy and J. H. Harding, Langmuir, 2004, 20, 7630.

14 S. Yamanaka, N. Ito, A. Shimosaka, Y. Shirakawa and J. Hidaka, Cryst. Growth Des., 2009, 9, 3245.

15 Q. Hu, M. H. Nielsen, C. L. Freeman, L. M. Hamm, J. Tao, J. R. I. Lee, T. Y. J. Han, U. Becker, J. H. Harding, P. M. Dove and J. J. D. Yoreo, Faraday Discuss., 2013, 159, 509.

16 A. Fernandez-Martinez, Y. Hu, B. Lee, Y.-S. Jun and G. A. Waychunas, Environ. Sci. Technol., 2013, 47, 102.

17 L. M. Hamm, A. J. Giuffre, N. Han, J. Tao, D. Wang, J. J. D. Yoreo and P. M. Dove, Proc. Natl. Acad. Sci. U.S.A., 2014, 111, 1304.
18 Q. Li, A. Fernandez-Martinez, B. Lee, G. A. Waychunas and Y.-S. Jun, Environ. Sci. Technol., 2014, 48, 5745.

19 N. R. Chevalier, J. Phys. Chem. C, 2014, 118, 17600.

20 P. J. M. Smeets, K. R. Cho, R. G. E. Kempen, N. A. J. M. Sommerdijk and J. J. De Yoreo, Nat. Mater., 2015, 14, 394.

21 Y.-S. Jun, D. Kim and C. W. Neil, Acc. Chem. Res., 2016, 49, 1681.

22 A. Al-Karaghouli and L. L. Kazmerski, Renew. Sustain. Energy Rev., 2013, 24, 343.

23 A. T. Paxson, J. L. Yagüe, K. K. Gleason and K. K. Varanasi, Adv. Mater., 2014, 26, 418.

24 W. C. Cheong, P. H. Gaskell and A. Neville, J. Cryst. Growth, 2013, 363, 7.

25 T. V. Charpentier, A. Neville, S. Baudin, M. J. Smith, M. Euvrard, A. Bell, C. Wang and R. Barker, J. Colloid Interface Sci., 2015, 444, 81.

26 A. M. Coclite, R. M. Howden, D. C. Borrelli, C. D. Petruczok, R. Yang, J. L. Yagüe, A. Ugur, N. Chen, S. Lee, W. J. Jo, A. Liu, X. Wang and K. K. Gleason, Adv. Mater., 2013, 25, 5392.

27 J. Zhao, M. Wang and K. K. Gleason, Adv. Mater. Interfaces, 2017, 4, 1700270.

28 H. Moon, H. Seong, W. C. Shin, W.-T. Park, M. Kim, S. Lee, J. H. Bong, Y.-Y. Noh, B. J. Cho, S. Yoo and S. G. Im, Nat. Mater., 2015, 14, 628.

29 N. J. Trujillo, Q. Wu and K. K. Gleason, Adv. Funct. Mater., 2010, 20, 607.

30 S. Kim, H. Sojoudi, H. Zhao, D. Mariappan, G. H. McKinley, K. K. Gleason and A. J. Hart, Sci. Adv., 2016, 2, e1601660.

31 W. S. O'Shaughnessy, M. Gao and K. K. Gleason, Langmuir, 2006, 22, 7021.

32 M. Gupta and K. K. Gleason, Langmuir, 2006, 22, 10047.

33 A. S. El Din, M. E. El-Dahshan and R. A. Mohammed, Desalination, 2005, 177, 241.

34 A. Perrotta, P. Christian, A. O. F. Jones, F. Muralter and A. M. Coclite, Macromolecules, 2018, 51, 5694.

35 J. C. Arnold, in Compr. Struct. Integr., ed. I. Milne, R.O. Ritchie and B. Karihaloo, Pergamon, Oxford, 2003, pp. 281-319.

36 G. L. Jialanella, in Adv. Struct. Adhes. Bond., ed. D.A. Dillard, Woodhead Publishing, 2010, pp. 237-264.

37 E. Barthel, J. Phys. D: Appl. Phys., 2008, 41, 163001.

38 R. Hidema, T. Toyoda, H. Suzuki, Y. Komoda and Y. Shibata, Int. J. Heat Mass Transf., 2016, 92, 603.

39 S. S. Lee, F. Heberling, N. C. Sturchio, P. J. Eng and P. Fenter, J. Phys. Chem. C, 2016, 120, 15216-15223.

40 A. J. Kinloch, J. Mater. Sci., 1980, 15, 2141-2166.

41 D. M. Mattox, in Handb. Phys. Vap. Depos. PVD Process, ed.

D. M. Mattox, William Andrew Publishing, 2nd edn, 2010, pp. 439-474.

42 O. Söhnel and J. W. Mullin, J. Cryst. Growth, 1978, 44, 377. $43 \mathrm{~W}$. Wu and G. H. Nancollas, Adv. Colloid Interface Sci., 1999, 79, 229.

44 A. G. I. Dalvi, N. M. Kither Mohammad, S. Al-Sulami, K. Sahul and R. Al-Rasheed, Desalination, 2000, 129, 173.

45 M. E. Berndt and W. E. Seyfried, Geochim. Cosmochim. Acta, 1999, 63, 373-381. 